ISSN: 2576-8875

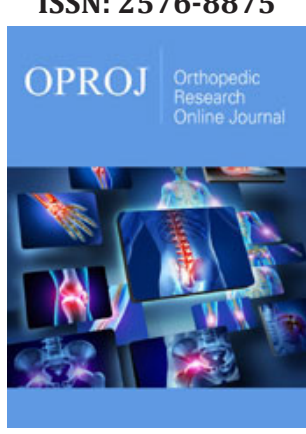

*Corresponding author: Srinath Kamineni, Department of Orthopaedics Surgery, Elbow Shoulder Research Centre, University of Kentucky, USA

Submission: 啙 August 03, 2020

Published: 制September 02, 2020

Volume 7 - Issue 3

How to cite this article: Ferras Albitar, Evan Carey, Srinath Kamineni. Manual Dexterity Training for Orthopaedic Residents - Non-Patient based Methodologies. Ortho Res Online J. 7(3). OPROJ. 000665. 2020.

DOI: 10.31031/OPROJ.2020.07.000665

Copyright@: Srinath Kamineni, This article is distributed under the terms of the Creative Commons Attribution 4.0 International License, which permits unrestricted use and redistribution provided that the original author and source are credited.

\section{Manual Dexterity Training for Orthopaedic Residents - Non-Patient based Methodologies}

\author{
Ferras Albitar, Evan Carey and Srinath Kamineni* \\ Department of Orthopaedics and Sports Medicine, University of Kentucky, USA
}

\begin{abstract}
Background: Orthopaedic surgical techniques are complex, rapidly evolving, and require significant training to attain competence. Hindrances to acquiring these complex skills during residency include: work hour restrictions, inconsistent case volumes, and policy changes centered on operating room (OR) efficiency and patient safety. The evolution of orthopaedic training in response to these challenges forced the development of non-patient-based training methods outside of the OR. Understanding how orthopaedic residents develop and retain surgical skills will hopefully provide more efficient training. The different methods, their respective advantages, and evidence of their efficacy is necessary to direct resident training in the future.
\end{abstract}

Methods: PubMed and Google Scholar were searched for literature related to orthopaedic resident training. The resulting articles were used to find other manuscripts pertinent to the subject. Training methods involving patients were excluded.

Results: Non-patient-based methods for orthopaedic resident surgical training include cognitive training for knowledge acquisition, low fidelity models for basic skills, bench-top models for arthroscopic skill development, cadaveric and animal models, synthetic bone models, and virtual reality simulators. Evidence for the type of training resulting in the most robust skills acquisition and retention, supports targeted, deliberate practice in spaced repetitions using a competency-based curriculum.

Conclusion: A variety of non-patient based methods exist for surgical skill development, aimed at mitigating challenges faced by orthopaedic residents. Despite their abundance, evidence supporting direct transfer of skills learned via these methods to the OR is rare in orthopedics. Barriers to their use and implementation, namely a lack of funding, are prevalent.

Keywords: Orthopaedics; Surgical education; Simulation; Arthroscopy; Clinical competence; Resident training

\section{Introduction}

Current orthopaedic trainees are given less time to achieve competency in increasingly complex and diverse surgical procedures compared to their predecessors [1,2]. The multitude of different surgical techniques that have emerged require volumes of supervised repetition to achieve competence. It can be considered that surgical competence for orthopaedic residents cannot be achieved solely by caseload alone in the time it takes to complete residency $[3,4]$. Multiple factors, detrimental to the goal of rigorous training can be identified, including resident work hour restrictions, increasing administrative duties and documentation, inconsistent case volumes, and other service related duties [5]. These challenges have been compounded with changes in healthcare policies that center on Operating Room (OR) efficiency, reaching quality assurance targets, patient safety, and reducing patient waiting times. Such issues have forced a dramatic deviation from the traditional paradigm of the teacher-apprentice model of professional training, previously followed for the last hundred years [6]. These evolving challenges have necessitated alternative strategies of skill acquisition, notably physical and virtual simulation, psychomotor training, cognitive training, and competency-based evaluation.

Since its implementation in 2003, the resident work hour restrictions enacted by the Accreditation Council for Graduate Medical Education (ACGME) have been met with mixed 
enthusiasm [7]. Opponents fear that resident education will suffer as a result. Fitzgibbons et al. [8] surveyed orthopaedic residents both before (2003) and after the restrictions (20042009), finding self-reported decreases in resident confidence in clinical preparedness, overall satisfaction in education, hours spent performing procedures on patients, and the adequacy of their clinical experience [8]. Zuckerman et al. [9] surveyed junior and senior orthopaedic residents as well as attending surgeons about their perceived effects of the work hour restrictions. Despite differences among the groups on other issues, there was general agreement that their operating experience had been negatively impacted. Ongoing innovation and research on how surgical training can improve efficiency and maximize skill acquisition has led to advances in understanding how residents learn surgical skills, the development of new teaching methodologies, and the implementation of new program requirements. These changes are evidenced by mandates applied in July 2013 from the ACGME and the American Board of Orthopaedic Surgery (ABOS), which now require six months of rotations in orthopaedic surgery as well a surgical skill training course for all orthopaedic interns. These mandates are an effort to combat the rapid expansion of different surgical techniques, increasing complexity of the procedures, and reduced OR time for orthopaedic residents from duty hour restrictions [10].

\section{How residents learn: maximizing efficiency and transferrable surgical skill acquisition}

Orthopaedic procedures require considerable psychomotor skill and knowledge, both concerning the procedure and pathoanatomy, in order to prevent iatrogenic injury to the patient $[11,12]$. Minimally invasive procedures such as arthroscopy present additional challenges such as the fulcrum effect, handeye coordination for triangulation, and visual-spatial coordination to construct 2-dimensional images into 3-dimensions $[11,13]$. The acquisition of orthopaedic surgical skills is exemplified by Fitts and Posner's three-stage theory of motor skill acquisition $[6,14,15]$. According to Fitts and Posner, there are 3 overlapping but progressive stages in the learning of any motor skill: cognition, integration, and automation (Figure 1) [16]. In the cognitive stage, performance is erratically non-fluid as the trainees attempt to intellectualize the task and understand the mechanics of the skill. In the integrative stage, the trainee is still gaining fluidity and efficiency, but still actively thinking about how to translate their knowledge into the appropriate motor movements. Once the automation stage is reached, execution of the task is precise, efficient, reflexive, allowing incorporation of other aspects of the procedure into their actions and decision making. Progression to each stage is mediated by external instruction, repeated practice, feedback, self-reflective audit, and confidence.

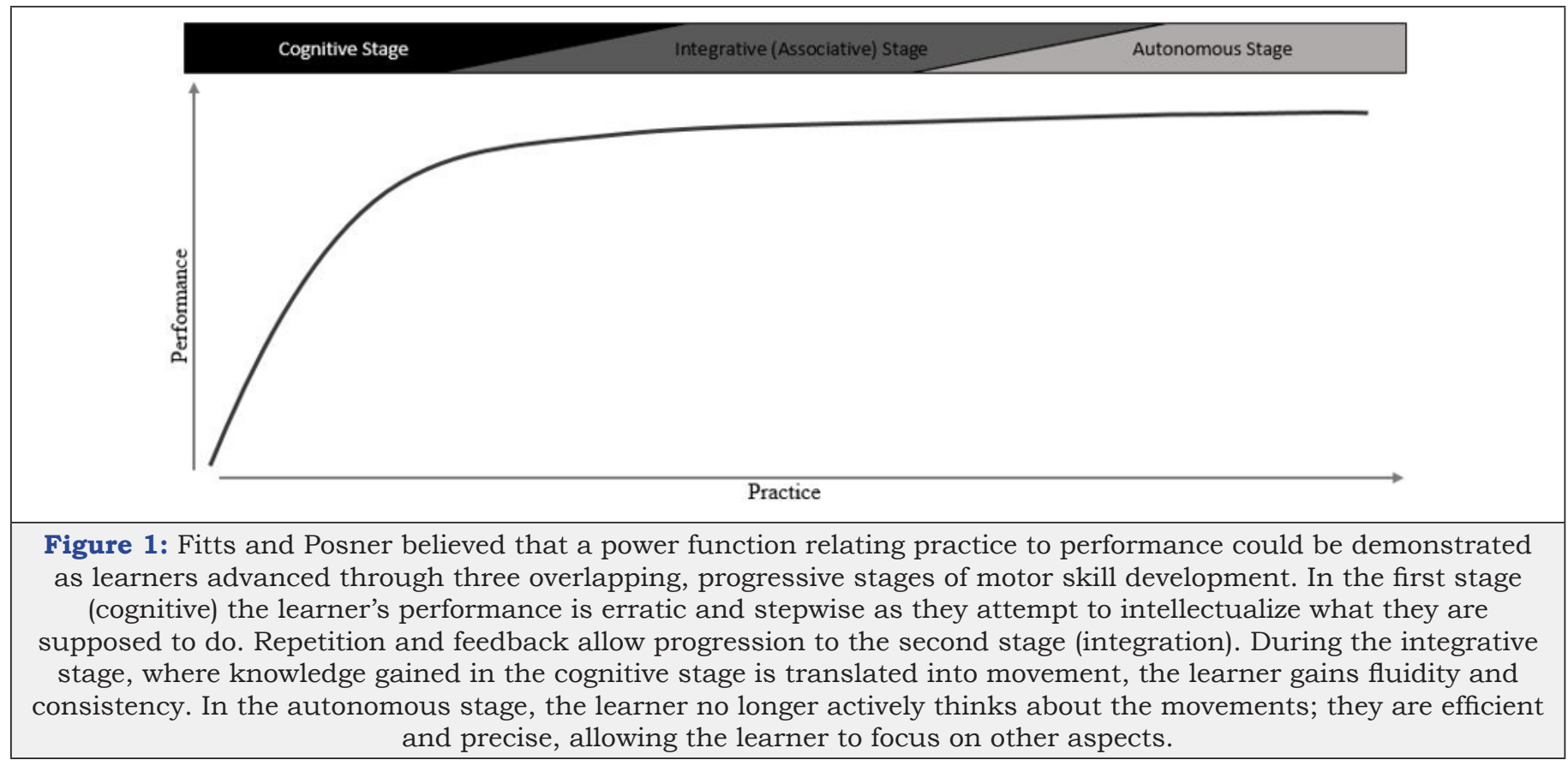

The type of practice for orthopaedic trainees matters. Deliberate practice with spaced repetition and feedback in a structured training format shows more robust retention (defined as durability of skill acquisition at one-month retesting) and greater transfer of skills to more realistic settings in surgical residents $[17,18]$. Deliberate practice also engages trainees in progressively challenging tasks, with immediate feedback on their performance, and the opportunity to improve by repeating the same or similar task, thereby correcting errors [19]. Increasing acceptance of the importance of deliberate practice, educational time constraints, and concerns for patient safety have forced curriculum reforms. The traditional Halstedain apprenticeship model of "see one, 
do one, teach one" has been augmented by the development and implementation of competency-based curriculums for residents, including orthopaedic training programs $[20,21]$. The justification behind competency based curriculums is driven by more efficient and effective training where residents progressed to the next learning objective only when they demonstrated competence, determined by specific assessment tools, notably the Objective Structural Assessment of Technical Skills (OSATS) [12,22-24]. The advantages of competence based progression is that residents are not constrained by a predetermined period of time for the development of skill; they can titrate time depending on their aptitude for a given training objective. In addition, the frequent assessments and evaluations provide residents with feedback, accelerating skill improvements.

The purpose of this review is to provide an overview of nonpatient based training methodologies for orthopaedic residents. The rationale for their use, as well as some of their proposed shortcomings, will be discussed.

\section{Cognitive training tools to enhance knowledge}

The development of orthopaedic surgical skill is a complex relationship based upon interaction between the cognitive (knowledge based) domain and the psychomotor (technical skill) domains [25]. Cognitive improvements such as anatomical understanding, tools used, individual steps of a procedure, and how each step is performed, may reduce the overall training time required to reach technical competence by giving meaning to the skills being practiced [26,27]. Knowledge acquisition and retention in medical education can be enhanced by engaging trainees in active learning methods in addition to standard passive learning such as didactic teaching or textbook reading [28]. Studies based on adult learning theories have shown that the learning curve of active learning is higher than that of passive learning [29].

E-learning is one way educators are attempting to maximize orthopedic resident knowledge while minimizing costs and instructor time commitment [30]. E-learning is internet and computer-based multimedia instruction with the ability to be accessed remotely and at any time (Table 1). Content can range from interactive online modules containing videos, radiographic images, and text to virtual reality environments and virtual patients [31]. Cook et al. [32] performed a 2010 meta-analysis on E-learning as an instructional tool for potential health professionals (students, residents, fellows, and practitioners) and found improved learning outcomes were significant when E-learning had the following characteristics: interactive elements, repetition of study materials, practice exercises/assessments, and feedback [32]. Commercially produced, comprehensive, web-based learning modules specifically designed for orthopaedic residents have already been produced, such as the ortho bullets PASS Curriculum (Lineage Medical, Santa Barbara, CA, USA). The PASS Curriculum, aimed at providing orthopedic residents with the knowledge and skills to be successful on the orthopedics In-Training Examination, was found to produce significant increases in resident scores and had a high level of resident satisfaction [33]. E-learning has the advantage of rapid updateability; new modules can be added, different surgeries and scenarios can be taught, and learning can be monitored by assessments in the module [34].

Table 1: Available non-patient based training methods.

\begin{tabular}{|c|c|c|c|}
\hline Training Modality & Advantages & Disadvantages & Best Use of Modality \\
\hline Cadavers & $\begin{array}{l}\text { Highest fidelity, evidence supporting } \\
\text { skill transfer } \\
\text { Complete osseous, soft tissue, \& } \\
\text { neurovascular elements facilitates } \\
\text { clinical anatomy knowledge } \\
\text { Whole procedures can be practiced }\end{array}$ & $\begin{array}{l}\text { Costly, difficult to acquire, store, } \\
\text { prepare } \\
\text { Ethics committee approval required } \\
\text { Risk of infection transmission } \\
\text { Individual anatomy lacks uniformity, } \\
\text { may be non-representative of the } \\
\text { overall patient population }\end{array}$ & $\begin{array}{l}\text { Complete procedural knowledge and } \\
\text { practice for learners who have progressed } \\
\text { through more basic training methods }\end{array}$ \\
\hline Animal Models & $\begin{array}{l}\text { High fidelity, allows use of real tissue } \\
\text { In vivo simulations allow practice of } \\
\text { hemostasis }\end{array}$ & $\begin{array}{l}\text { Costly, time intensive preparations } \\
\text { Requires ethical approval, facilities \& } \\
\text { personnel Anatomical differences }\end{array}$ & $\begin{array}{l}\text { Learning dissection, vascular \& soft } \\
\text { tissue influences for advanced procedural } \\
\text { techniques }\end{array}$ \\
\hline Arthroscopic Simulation & $\begin{array}{l}\text { Exposure to instruments \& the } \\
\text { inherent difficulties of arthroscopy } \\
\text { Newer models incorporate haptics, } \\
\text { data capture }\end{array}$ & $\begin{array}{l}\text { High initial cost } \\
\text { Difficult to simulate 3-D environment } \\
\text { \& live human tissue }\end{array}$ & $\begin{array}{c}\text { Development of ability to construct mental } \\
\text { 3-D environment from 2-D images, manual } \\
\text { dexterity }\end{array}$ \\
\hline $\begin{array}{l}\text { Virtual Reality +/- Haptic } \\
\text { Feedback }\end{array}$ & $\begin{array}{l}\text { Reusable, minimal maintenance } \\
\text { costs } \\
\text { Allows analysis \& recording of } \\
\text { individual progress } \\
\text { Able to simulate different scenarios, } \\
\text { including patient specific imaging } \\
\text { data }\end{array}$ & $\begin{array}{l}\text { High initial cost Difficult to simulate } \\
\text { 3-D environment \& live human tissue }\end{array}$ & $\begin{array}{c}\text { Situational practice and the development of } \\
\text { procedural knowledge }\end{array}$ \\
\hline
\end{tabular}




\begin{tabular}{|c|c|c|c|}
\hline Synthetic Bones & $\begin{array}{c}\text { Widely available, inexpensive, easily } \\
\text { transported } \\
\text { Allows familiarity with relevant } \\
\text { osseous anatomy }\end{array}$ & $\begin{array}{l}\text { Limited realism, lacks surrounding } \\
\text { neurovascular \& soft tissue elements } \\
\text { Lacks the true haptics of real bone }\end{array}$ & $\begin{array}{l}\text { Learning biomechanics of bones , fracture } \\
\text { reduction, drilling, screw placement, } \\
\text { fixation, \& plating techniques }\end{array}$ \\
\hline $\begin{array}{l}\text { Surgical Skills } \\
\text { Laboratories }\end{array}$ & $\begin{array}{c}\text { Exposure to instruments, } \\
\text { techniques, \& procedures } \\
\text { Allows intensive training in a } \\
\text { supervised environment that can } \\
\text { provide feedback }\end{array}$ & $\begin{array}{l}\text { Potential to be costly } \\
\text { Time, space, \& personnel intensive } \\
\text { Limited realism in many of the } \\
\text { stations }\end{array}$ & $\begin{array}{l}\text { Learning basic skills, team building, } \\
\text { targeted practice in a controlled setting }\end{array}$ \\
\hline $\begin{array}{l}\text { Task Trainers (Low } \\
\text { Fidelity Bench Models) }\end{array}$ & $\begin{array}{l}\text { Low cost, allows repeated exposure } \\
\text { to basic tasks } \\
\text { Simplicity, allows breakdown of } \\
\text { complex procedures into component } \\
\text { parts }\end{array}$ & $\begin{array}{c}\text { Limited realism } \\
\text { Lacks complexity \& the influence of } \\
\text { soft tissues } \\
\text { Breakdown of complex tasks } \\
\text { into simple components may be } \\
\text { detrimental to overall procedural } \\
\text { fluidity }\end{array}$ & $\begin{array}{l}\text { Learning discrete skills through repetition } \\
\text { for novice learners }\end{array}$ \\
\hline $\begin{array}{l}\text { Cognitive Enhancement } \\
\text { Tools (e.g. E-learning) }\end{array}$ & $\begin{array}{l}\text { May reduce overall training time to } \\
\text { competency } \\
\text { Ease of accessibility, updateability } \\
\text { Minimizes instructor time } \\
\text { commitment } \\
\text { Provides feedback \& tracks progress }\end{array}$ & $\begin{array}{l}\text { Does not replace face-to-face } \\
\text { instructor teaching } \\
\text { Limited evidence for effectiveness in } \\
\text { orthopaedic training }\end{array}$ & $\begin{array}{l}\text { Basic understanding of anatomy, tools, and } \\
\text { procedures step by step before physical } \\
\text { practice methods }\end{array}$ \\
\hline
\end{tabular}

There have been several E-learning modules produced and tested for orthopedic resident education. Hearty et al. found that resident instruction via an E-learning training module was more effective than simply reading textbooks in preparation for an actual closed reduction and pinning of pediatric supracondylar fracture based on multiple choice question testing and subjective feedback from the attending surgeons after the case [30]. The residents selfreported greater confidence, with less anxiety in the OR after the module, however, objective measures of surgical performance were not evaluated. Another E-learning module has been developed and tested on orthopaedic residents that walks the trainee through the steps of a simulated hip fracture repair [35,36]. It allows the trainee to click through relevant steps, and make decisions about specific aspects of the procedure. Importantly, the module was able to discriminate between surgical experience, by measuring and providing feedback on incision length, final screw placement, misplaced drill-holes, reduction position, the number of radiographs taken, and the total surgical time to completion. Similar E-learning modules have been developed to teach orthopedic trainees pedicle and sacroiliac screw insertion, with the added advantage that patient specific imaging data can be used in the module $[37,38]$.

While E-learning has been accepted by medical student educators as a useful tool for teaching theoretical knowledge, we were unable to find any study demonstrating improved orthopaedic surgical performance with its use [39-42]. E-learning does have its shortcomings and cannot completely replace face to face education.
It is merely a tool to augment the interactions between instructors and trainees [34]. The effectiveness of E-learning is also affected by the content in the modules, requiring elements such as interactivity, evaluations, and feedback in order to be truly more effective than just reading a textbook [32].

\section{Simulation}

Simulation in medical education has emerged out of necessity. The apprenticeship model where residents would learn surgical skills in the OR under the guidance of a mentor are no longer feasible due to the current constraints within medicine. The aforementioned challenges to resident training such as work hour restrictions, ethical considerations, and hospital policies aimed at minimizing costs, have produced a new model of surgical education where skills are learned and refined outside the OR [6,12]. The goals of skill acquisition via simulation and models (Table 1 ) is to prepare the surgical residents for the $\mathrm{OR}$, as there is no true substitute that can mimic all the aspects of a real surgery [34].

Orthopaedic resident involvement in surgery has generally been associated with prolonged operative times in large scale analyses [43-45]. Despite concerns over patient safety and the risks associated with prolonged operative times such as infection and pulmonary embolism, intraoperative participation by residents was not associated with increased complications, readmission, reoperation or mortality in an analysis done by the 2011 American College of Surgeons National Surgical Quality Improvement Program (ACS-NSQIP) of 30,628 patients from over 250 
institutions comprising both teaching and non-teaching hospitals who underwent orthopaedic procedures [43]. These findings are confirmed by most studies [44-48] with the exception of one study finding increased complications when residents were present in joint arthroplasty cases [49]. However, these studies did not describe the level of intraoperative and perioperative involvement of the resident. One study found no difference in short term clinical outcomes in patients who underwent total hip arthroplasty performed by an attending surgeon compared to a resident under direct supervision of an attending [50].

Prolonged operative times, do however, translate into increased costs, and with the average cost of OR time in the United States at $\$ 68 /$ minute (Range $\$ 22-\$ 133$, excluding the surgeon and anesthesia provider fees) it is a significant burden to the healthcare system [51]. For an arthroscopic Anterior Cruciate Ligament (ACL) repair, one study found increased operative times leading to an average OR cost increase of $\$ 661.85$ per case, when performed by a senior orthopedic resident [52]. The increased time spent in the OR, as well as fears over patient safety can be lessened by having residents learning outside the OR. Non-orthopaedic residents trained on simulators before entering the OR have been shown to reduce OR time, make fewer errors, and have better economy of movement for both laparoscopic and open procedures [6,53,54]. However, in orthopaedics, there is a paucity of studies that demonstrate direct transfer of skills to the operating room. At present, we were able to find 3 studies that showed improved operating performance after residents were trained on simulators $[53,55,56]$.

Despite agreement among orthopaedic residents and program directors that surgical skill acquisition outside the operating room should be expanded, a 2013 survey found that $25 \%$ of orthopaedic residency programs did not have a dedicated skills training area at their institution $[57,58]$. Most $(87 \%)$ of the program directors cited lack of funding as the main barrier to implementation of surgical skills labs, indicating the need for cost-effective simulations that provided measureable skills improvement as well as more return on investment studies in orthopaedic education.

\section{Low fidelity models for basic skill acquisition}

The general rule for simulation is that with higher fidelity comes higher cost [6]. Low fidelity models are the most economical of the simulators and can be effective tools in training if developed and used correctly [12]. By providing exposure to the instruments and basic fundamental steps of procedures, low fidelity simulator training can lay the foundation for progression through competencebased orthopaedic training. Because of the low costs, these training tools allow repetitive, deliberate practice of a particular skill distributed over an extended period of time. This has been shown to translate into better retention of the psychomotor skills due to long-term structural modifications in associated pathways in the brain [59].

Low fidelity tools designed for orthopaedic education include microsurgery fundamentals training using a latex glove, knot tying exercises on a knot tying board, and bone drilling on PVC pipes [6062]. Surgical skills labs have been developed and implemented as part of PGY-1 competency-based curriculum that combine different models and simulated tasks with objective assessments [59,61]. Labs that implement progression from low fidelity to more realistic simulations upon demonstration of competency, have also been shown to be effective in increasing orthopaedic resident skills [62].

The advantage of basic skills training is that it allows for the component steps of complex surgeries to be segmented, allowing the learner to focus on developing cognitive and psychomotor skills 50. These skills require less attention as the trainee progresses through the integration and automation stages, as they practice in preparation for the actual surgery [54]. However, there are disadvantages to fragmenting a complex procedure into its simpler component parts. Studies found that if practice for a complex motor task such as bi-cortical bone plating using a fractured cadaver bone is broken down into separate component parts, trainees did not perform as well as those who practiced the whole task from start to finish, a concept termed "functional order practice" $[63,64]$. Explanations for these findings postulate the idea that when stringing together subcomponents, transitioning between the different skills altered the kinematic characteristics of the individual components in anticipation of the next elements of the task $[65,66]$.

\section{Benchtop models for arthroscopic skill acquisition}

Arthroscopy requires a special skillset, involving dexterity, hand-eye coordination in a visual plane, and the ability to know and identify anatomy despite varying degrees of arthroscope offset [67]. Development of the basic motor skills required for arthroscopy such as visual-spatial perception, coordination, and familiarity with the fulcrum effect are benefitted more by factors like repetition and feedback compared to how realistic the simulator is [68]. With this in mind, several low cost arthroscopic simulators were developed that consisted of a trainer box with prefabricated ports, an optical system (arthroscope, light source, camera, and video monitor), and internal components that could be rapidly swapped out based on which skill was being simulated. Skills taught via these methods included arthroscopic knot tying, suture passing, probing, grasping, and triangulation (Figure 2A \& 2B) [68-70]. More complex skills such as tissue resection, shaving, and liberation were also simulated with synthetic materials placed in the trainer. Importantly, these low fidelity models show promising results in resident training when combined as part of an arthroscopic skills laboratory and objectively assessed as part of a competence based curriculum $[61,68,71]$. 

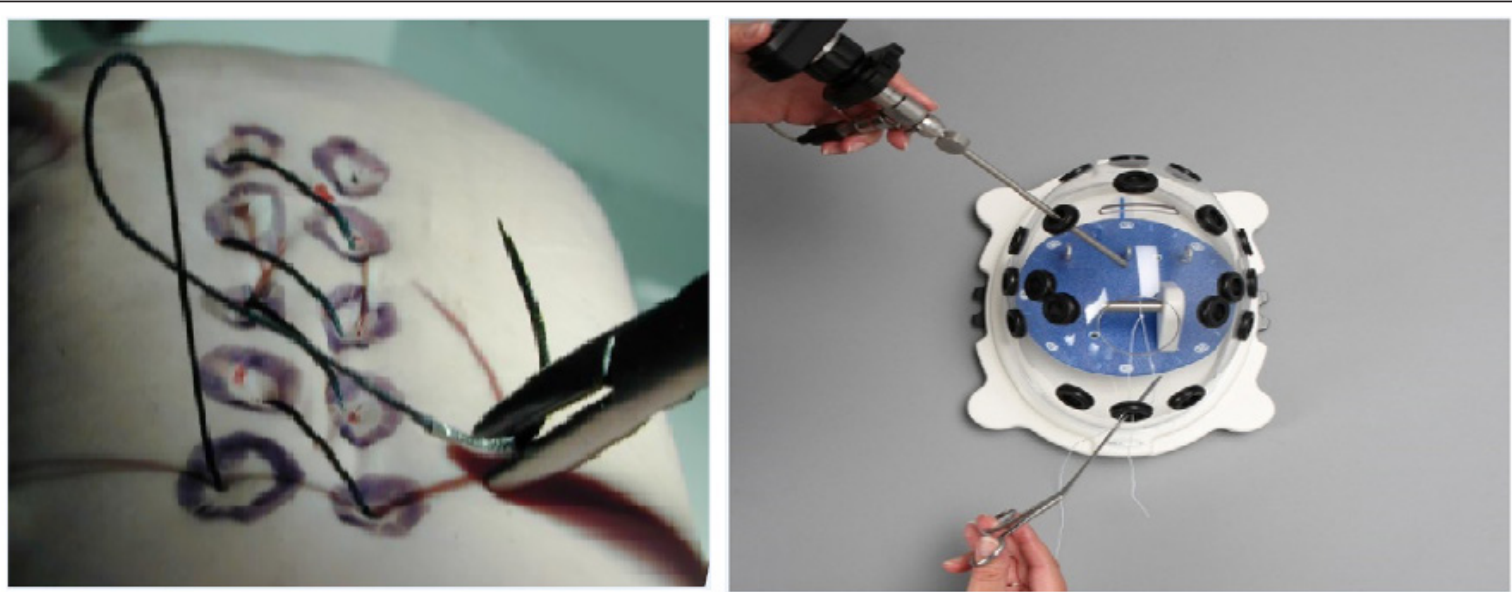

Figure 2: Benchtop arthroscopic skill simulation. (A) View under a handmade box for simulation of intracorporal suturing created at our institution. The trainee views the contents of the box through a camera attached to a monitor and manipulates the suture with a needle holder via a portal in the box. (B) Fundamentals of Arthroscopic Surgery Training (FAST) workstation, with the knot tying module in place. Figure 2(B) courtesy of Pacific Research Laboratories, Inc. (Sawbones).

Despite their simplicity and low fidelity, Howells et al. [55] demonstrated reliable transfer of skills and psychomotor efficiency from a benchtop arthroscopic simulator to the OR. Orthopedic residents were trained over a period of 3 weeks to perform a total of 18 simulated diagnostic knee arthroscopies each, while objective metrics such as the number of hand movements, path length, and time taken were monitored by a motion capture system. The motion analysis showed statistically significant learning curves $(p=0.001)$ in all three-objective metrics during the subsequent training sessions on the simulator. The simulator trained residents then scored significantly higher when assessed by a blinded expert compared to the control group when performing a diagnostic knee arthroscopy on a patient in the operating theatre.

\section{Cadaver based simulation}

Since its origins in the sixteenth century, surgical education using cadavers remains the most realistic simulation method [1]. Cadavers expose trainees to real anatomy and variations that can be encountered in patients (Figure 3A \& 3B). The ability to handle soft tissue and experience planes of dissection is something that no other simulation except for animal models can provide. However, the degree of fidelity depends on the condition of the cadaver (fresh versus embalmed, age of death, etc.) and the simulation design [72]. In support of this belief, Camp et al. [73] found that residents trained in diagnostic knee arthroscopy on a cadaver performed better than those who trained using a VR simulator, indicating disparity between the two simulations. Cadavers, however, have high costs associated with acquiring, preparing, and storing the specimens, making repetition impractical [21]. There is also the risk of disease transmission with fresh cadavers, as well as the disproportionate representation of the elderly population whose bone composition may differ from the general orthopedic patient population.
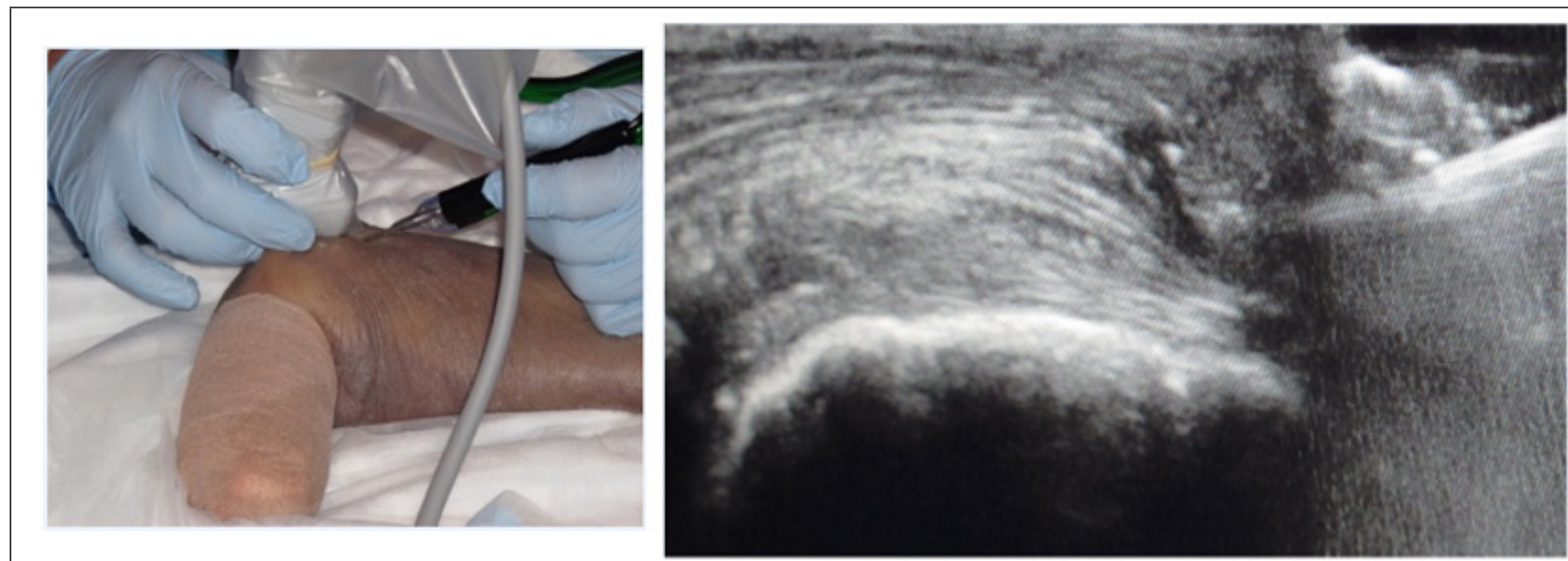

Figure 3: (A) Cadaver based training of an ultrasound guided percutaneous tennis elbow debridement. (B) Ultrasound image of the surgical probe within the extensor mass of the elbow. 
Simulated open and arthroscopic procedures have been developed using cadavers as training and assessment tools. Van Heest et al. [74] developed an open carpal tunnel release simulation based on cadavers that showed demonstrable differences in OSATS score that correlated with surgeon experience, indicating construct validity. Construct validity in a simulator is determined by its ability to accurately measure the specific qualities that it was designed to measure. In this case it was to demonstrate differences between novices and experts in performance metrics. Furthermore, construct validity may highlight metrics or exercises relevant to becoming a competent surgeon [75].

Several studies with small subject populations have demonstrated rapid improvement in drilling and placement of thoracic pedicle screws using cadaver specimens [76,77]. In a study by Bergesen et al. [76] three orthopaedic residents were given didactic instruction by an expert surgeon and then allowed to place a total of 297 thoracic pedicle screws in 149 cadaver vertebrae (5 cadavers per resident). When the procedure was analyzed by an expert surgeon, the percentage of misplaced screws was reduced from $34 \%$ in the first cadaver to $15 \%$ in the final cadaver. In a similar study, Tortolani et al. [77] used computed tomography to evaluate placement of thoracic pedicle screws by 3 residents, who were trained using repeated attempts of screw placement on cadaver specimens. Trainees showed improvement in correct placement from $44 \%$ in the first cadaver to $58 \%$ in the final cadaver.

Arthroscopic training using cadaver models has also been shown to have construct validity by several studies. A 2015 study by Angelo et al. [78] showed significant performance differences between residents and experienced surgeons performing diagnostic arthroscopy with 3 suture anchor Bankart repair on cadavers [78]. The residents required more time for the procedure ( 45.5 versus 25.9 minutes) and made $50 \%$ more errors as assessed by blinded expert evaluators. These findings were similar to a previous study evaluating performance of a diagnostic knee [72]. Despite the ability for objective evaluation of arthroscopic performance using cadaver models to correlate with real world experience, the substantial overall costs associated with cadavers, as well as the rapid advances in VR technology, has led some groups to argue that VR based arthroscopic training may be a more effective training method based on cost-benefit analysis [73].

\section{Animal models}

Animal models as a method for surgical skill acquisition provides the benefit of allowing the trainee to handle real tissue, whose tactile properties are unaltered by formalin. Anesthetized, live animals can be used for training in vascular complications, such as bleeding [67]. However, animal models have similar drawbacks to cadavers due to ethical considerations, as well as the fact that most are not reusable, and the associated costs can be significant.

Simple training methods using animal parts, such as porcine joints and bones reduce the costs associated with keeping and anesthetizing live animals. A study by Leong et al. [2] comparing fracture fixation of porcine models to synthetic bone models for the assessment of technical skills showed that the porcine model was more sensitive for detecting differences in skill levels compared to the synthetic bone models [2]. These differences correlated with surgeon experience performing the procedure on patients. More realistic, complicated simulations such as a microvascular training course using anesthetized rats have been developed [62]. Supplemented with non-living, low fidelity models and expert instruction, orthopedic residents were allowed to repeatedly perform end to end femoral artery anastomosis under microscopy on these rats. The femoral artery was chosen as the authors believed that it closely mimicked the human digital artery. At the end of the training, patency of the vessel was achieved in $11 / 12$ orthopaedic residents involved compared to only $6 / 12$ without the training. Additionally, Global Rating Scores improved significantly for the majority of trainees.

\section{Synthetic bones}

Composite bones have been a mainstay of orthopedic simulation due to their ability to mimic bone architecture and physical properties (Figure $4 \& 5 \mathrm{~A}$ ) [79]. These bones can be purchased from multiple vendors and significantly more cost effective than cadaveric bones for teaching and understanding the biomechanics of real bones [80]. However, there are limitations to these replicas, as they do not completely emulate the viscoelastic properties, nor the internal architecture of real bone [81]. Composite bones have been used as tools for the development of a variety of orthopaedic skills such as fracture reduction, drilling, screw placement, fixation, and plating, as well as aspiration practice and arthroscopic skills (Figure 5B \& 5C) [82]. The relatively low cost, coupled with the ability to reuse the models, allows for spaced repetition and deliberate practice of skills resulting in enhanced long-term retention of skills $[71,82]$.

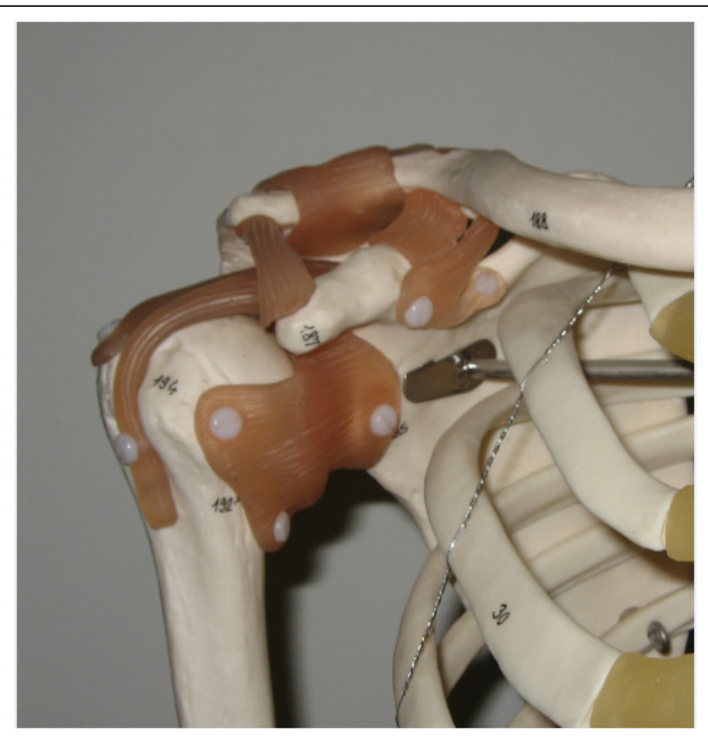

Figure 4: Close up view of a traditional, non-cadaveric skeleton with articulated joints and ligaments. 

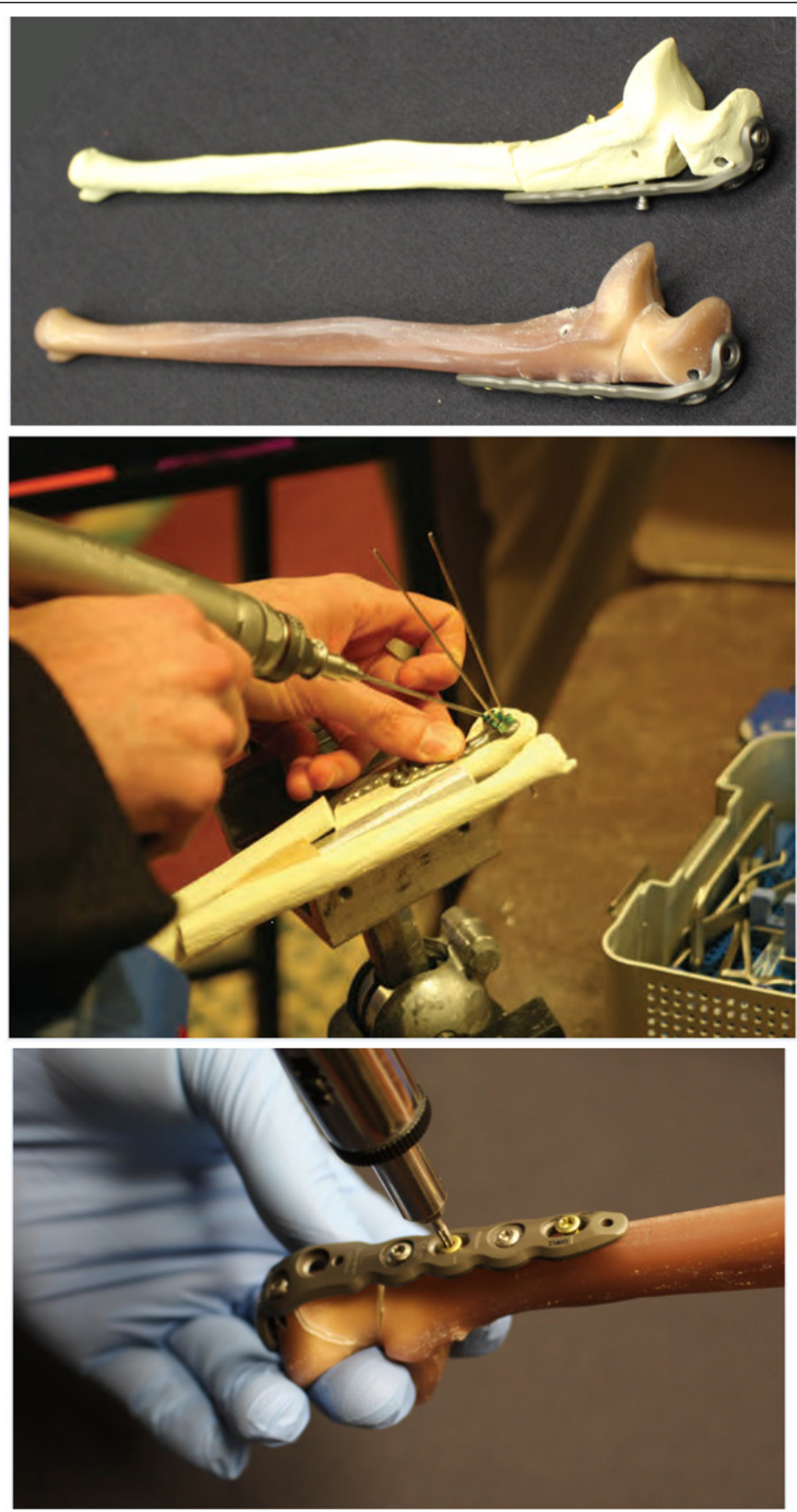

Figure 5: (A) First generation (top) and fourth generation (bottom) composite bone models. The fourth-generation model has a polyurethane foam core surrounded by epoxy resin reinforced glass fibers to replicate cancellous and cortical bone, respectively. (B \& C) Simulated fracture fixation using composite bones. The fourth-generation model replicates cadaveric bone when placed under drilling, bending, axial, and torsional loads due to their materials and manufacturing process. Figure 5(B) courtesy of Pacific Research Laboratories, Inc. (Sawbones).

Composite bones can be used alone, as low fidelity simulators, or they can be combined with other, commercially available, synthetic materials to mimic soft tissue elements. Simple, low fidelity models using composite bones can be used as task trainers, designed to provide repeated exposure to a portion of a more complicated procedure until familiarity with the instruments and movements is achieved. Additional complexity and realism can be achieved by using radiopaque bones and fluoroscopy [83]. Despite the benefits to novice surgeons, these added levels of complexity, and attempts at realism, a comparison of synthetic bones to porcine models, led to skepticism concerning whether or not synthetic bones have the fidelity to fine tune skills for more advanced surgeons [2,81]. 


\section{Virtual reality}

Virtual reality (VR) simulators have vastly improved, made possible by advances in computer technologies. VR simulators have differing levels of fidelity based on complexity and haptics in the form of tactile feedback. Haptics can provide either active or passive feedback. Computer generated mechanical resistance in response to the actions performed is provided by active haptics. Passive haptics provides mechanical resistance as soon as the instruments are picked up, adjusting the ease of probe movements based on the simulated action currently being performed [1]. Regardless of the fidelity and the presence or absence of haptics, VR allows repeated rehearsal of a surgical procedure or aspects of a procedure in an imagined 3-dimensional space (Figure 6A \& 6B).

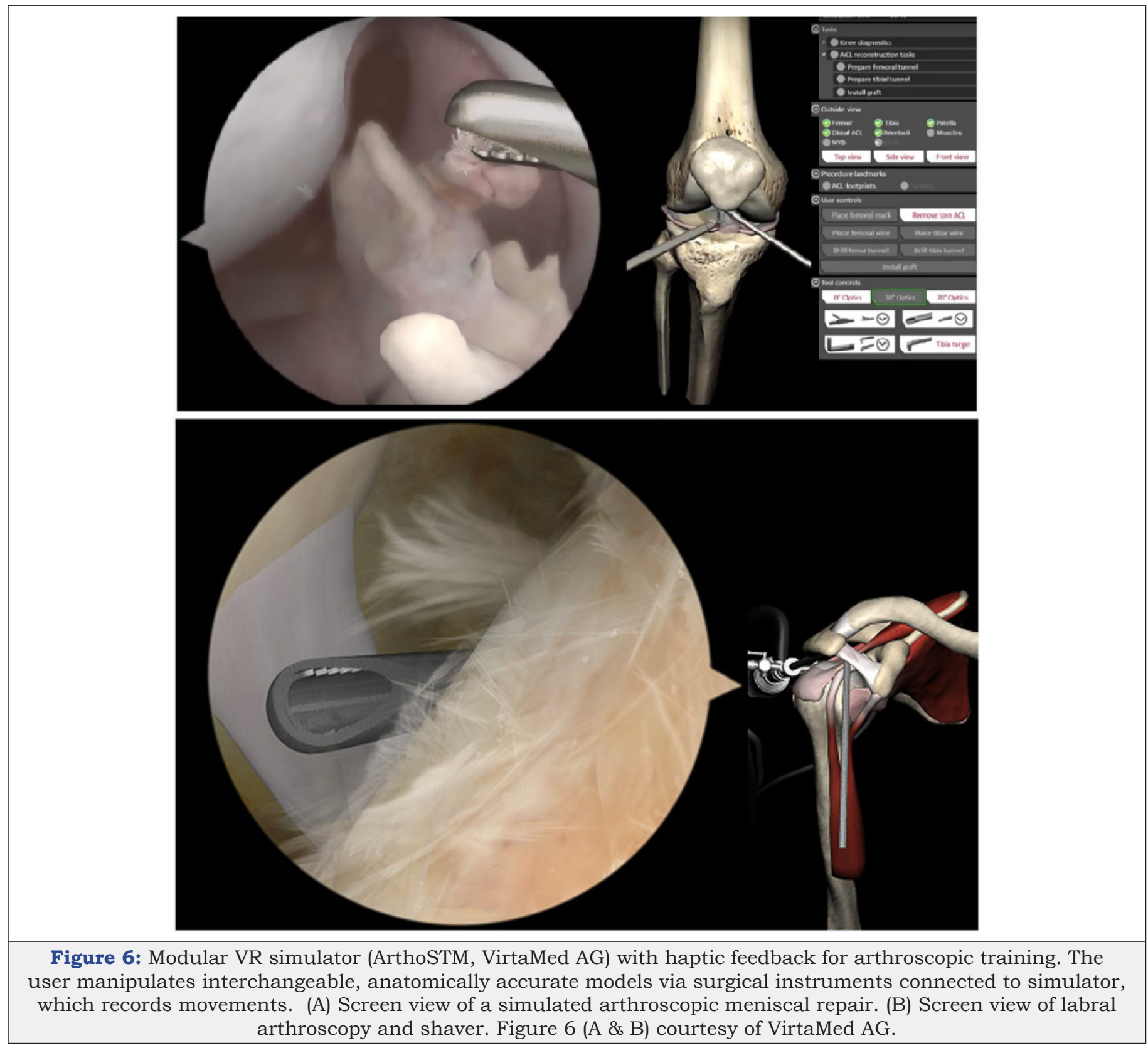

Despite the potentially large initial cost of buying the interface and software, VR has several advantages over other methods of simulation. The machine can be used repeatedly, with minimal maintenance. In addition, all aspects of the simulation can be monitored and recorded, providing immediate feedback and tracking of progress [84]. Monitoring hand movements, operator efficiency, and accuracy is crucial to improving psychomotor training and reducing operating time. Arguably, the most exciting aspect of virtual reality simulation is the ability to combine patient specific MRI or CT data with haptic feedback [85]. This allows for exposure to anatomical variations between different patients, the ability face potential intra-operative difficulties that may arise, and pre-operative planning on how to best treat each patient. 
At the time of writing, we found 2 studies that directly showed transfer validity of a VR trainer for orthopedic residents performing in vivo diagnostic arthroscopy [53,56]. A 2014 randomized control, single blinded study by Cannon et al. [53] showing improved performance of orthopedic residents in diagnostic knee arthroscopy after interval training for an average of 11 hours on a high fidelity VR simulator [53]. The second and most recent evidence, comes from a 2016 randomized control, single blinded study by Waterman et al. [56] showing improved performance in diagnostic shoulder arthroscopy when orthopaedic residents trained on a high-fidelity VR trainer [56].

Multiple studies have investigated the ability of VR surgical simulators to distinguish between differing skill levels of the operator and objectively assess trainee skill progression. Two large systematic reviews of orthopaedic simulator training found that real world experience correlated with operator performance on arthroscopic simulators [11,12]. Despite studies demonstrating transfer of surgical skills acquired via laparoscopic VR training to the OR for non-orthopaedic residents, these systematic reviews found that there was a paucity of evidence that actually correlates simulator performance to performance in the OR specifically for orthopaedic procedures [86,87].

\section{Areas for future research}

A 2013 nationwide survey of orthopaedic residents and program directors by Karam et al. [58] showed widespread support for simulation in resident education [58]. Of the 687 orthopaedic residents and 86 program directors that responded, there was agreement that surgical simulation should be a mandatory part of the curriculum by $86 \%$ of residents and $80 \%$ of directors. However, only $76 \%$ of the program directors reported having dedicated surgical skills laboratories. Furthermore, only $46 \%$ of these programs with had a structured surgical skills curriculum, with a majority of respondents (87\%) citing a lack of funding as the main barrier to creation and implementation.

\section{Conclusion}

Implementing new training methods will undoubtedly have increased costs and faculty time commitments, but these may be offset by increased return on investment [88]. Studies demonstrating return-on-investment for these new, alternative methods may persuade more administrations to invest in simulation. However, these studies are complex and orthopedic specific studies are rare [21]. The skills required to produce competent orthopaedic surgeons are a complex, inter-woven combination of physical and conceptual knowledge, translated into diagnostic and therapeutic ability. The latter, in particular, relies on manual dexterity and repetition under supervision. Investment at this 'ground-level' is crucial to propel this surgical specialty to higher levels in the future.

\section{References}

1. Atesok K, Mabrey JD, Jazrawi LM, Egol KA (2012) Surgical simulation in orthopaedic skills training. J Am Acad Orthop Surg 20: 410-422.
2. Leong JJ, Leff DR, Das A, Aggarwal R, Reilly P, et al. (2008) Validation of orthopaedic bench models for trauma surgery. J Bone Joint Surg $\mathrm{Br}$ 90(7): 958-965.

3. Morgenstern R, Morgenstern C, Yeung AT (2007) The learning curve in foraminal endoscopic discectomy: experience needed to achieve a $90 \%$ success rate. SAS J 1(3): 100-107.

4. Wang B, Lu G, Patel AA, Ren P, Cheng I (2011) An evaluation of the learning curve for a complex surgical technique: the full endoscopic interlaminar approach for lumbar disc herniations. Spine J 11(2): 122130 .

5. Bell RH (2007) Surgical council on resident education: a new organization devoted to graduate surgical education. J Am Coll Surg 204(3): 341-346.

6. Reznick RK, MacRae H (2006) Teaching surgical skills--changes in the wind. N Engl J Med 355(25): 2664-2669.

7. Harris JD, Staheli G, LeClere L, Andersone D, McCormick F (2015) What effects have resident work-hour changes had on education, quality of life, and safety? A systematic review. Clin Orthop Relat Res 473(5): 1600-1608.

8. Fitzgibbons SC, Chen J, Jagsi R, Weinstein D (2012) Long-term follow-up on the educational impact of ACGME duty hour limits: a pre-post survey study. Ann Surg 256(6): 1108-1112.

9. Zuckerman JD, Kubiak EN, Immerman I, Dicesare P (2005) The early effects of code 405 work rules on attitudes of orthopaedic residents and attending surgeons. J Bone Joint Surg Am 87(4): 903-908.

10. Dougherty PJ, Marcus RE (2013) ACGME and ABOS changes for the orthopaedic surgery PGY-1 (intern) year. Clin Orthop Relat Res 471(11): 3412-3416.

11. Frank RM, Erickson B, Frank JM, Bush-Joseph CA, Bach BR, et al. (2014) Utility of modern arthroscopic simulator training models. Arthroscopy 30(1): 121-133.

12. Thomas GW, Johns BD, Marsh JL, Anderson DD (2014) A review of the role of simulation in developing and assessing orthopaedic surgical skills. Iowa Orthop J 34: 181-189.

13. Nisky I, Huang F, Milstein A, Pugh CM, Mussa-Ivaldi FA, Karniel A (2012) Perception of stiffness in laparoscopy - the fulcrum effect. Stud Health Technol Inform 173: 313-319.

14. Fitts PM, Posner MI (1967) Human performance. Belmont, Brooks/Cole Pub. Co., California, USA.

15. Kopta JA (1971) The development of motor skills in orthopaedic education. Clin Orthop Relat Res 75: 80-85.

16. Taylor JA, Ivry RB (2012) The role of strategies in motor learning. Ann N Y Acad Sci 1251: 1-12.

17. McGaghie WC, Issenberg SB, Cohen ER, Barsuk JH, Wayne DB (2011) Does simulation-based medical education with deliberate practice yield better results than traditional clinical education? A meta-analytic comparative review of the evidence. Acad Med 86(6): 706-711.

18. Moulton CA, Dubrowski A, Macrae H, Graham B, Grober E, et al. (2006) Teaching surgical skills: what kind of practice makes perfect?: a randomized, controlled trial. Ann Surg 244(3): 400-409.

19. Ericsson KA (2004) Deliberate practice and the acquisition and maintenance of expert performance in medicine and related domains. Acad Med 79: S70-81.

20. Ferguson PC, Kraemer W, Nousiainen M, Safir O, Sonnadara R, et al. (2013) Three-year experience with an innovative, modular competencybased curriculum for orthopaedic training. J Bone Joint Surg Am 95(21): e166.

21. Nousiainen MT, McQueen SA, Ferguson P, Alman B, Kraemer W, et al. (2016) Simulation for teaching orthopaedic residents in a competencybased curriculum: Do the benefits justify the increased costs? Clin Orthop Relat Res 474(4): 935-944. 
22. Faulkner H, Regehr G, Martin J, Reznick R (1996) Validation of an objective structured assessment of technical skill for surgical residents. Acad Med 71(12): 1363-1365.

23. Hodgins JL, Veillette C (2013) Arthroscopic proficiency: methods in evaluating competency. BMC Med Educ 13: 61.

24. Martin JA, Regehr G, Reznick R, MacRae H, Murnaghan J, et al. (1997) Objective structured assessment of technical skill (OSATS) for surgical residents. Br J Surg 84(2): 273-278.

25. Luft AR, Buitrago MM (2005) Stages of motor skill learning. Mol Neurobiol 32(3): 205-216.

26. Kohls-Gatzoulis JA, Regehr G, Hutchison C (2004) Teaching cognitive skills improves learning in surgical skills courses: a blinded, prospective, randomized study. Can J Surg 47(4): 277-283.

27. Wulf G, Shea C, Lewthwaite R (2010) Motor skill learning and performance: a review of influential factors. Med Educ 44(1): 75-84.

28. Akaike M, Fukutomi M, Nagamune M, Fujimoto A, Tsuji A, et al. (2012) Simulation-based medical education in clinical skills laboratory. J Med Invest 59(1-2): 28-35.

29. Sprawls P (2008) Evolving models for medical physics education and training: a global perspective. Biomed Imaging Interv J 4(1): e16.

30. Hearty T, Maizels M, Pring M, Mazur J, Liu R, et al. (2013) Orthopaedic resident preparedness for closed reduction and pinning of pediatric supracondylar fractures is improved by e-learning: a multisite randomized controlled study. J Bone Joint Surg Am 95(17): e1261-1267.

31. Bamford R, Coulston J (2016) Effective e-learning in surgical education: the core values underpinning effective e-learning environments and how these may be enhanced for future surgical education. Ecancermedicalscience 10: ed53.

32. Cook DA, Levinson AJ, Garside S, Dupras DM, Erwin PJ, et al. (2010) Instructional design variations in internet-based learning for health professions education: a systematic review and meta-analysis. Acad Med 85(5): 909-922.

33. Boody B, Johnson P, Pugely A, Miller D, Geller J, et al. (2016) Validation of a web-based curriculum for resident education in orthopedic surgery. J Surg Educ 73(6): 1060-1065

34. Obdeijn MC, Bavinck N, Mathoulin C, van der Horst CM, Schijven MP, et al. (2015) Education in wrist arthroscopy: past, present and future. Knee Surg Sports Traumatol Arthrosc 23(5): 1337-1345.

35. Blyth P, Stott NS, Anderson IA (2007) A simulation-based training system for hip fracture fixation for use within the hospital environment Injury 38(10): 1197-1203.

36. Blyth P, Stott NS, Anderson IA (2008) Virtual reality assessment of technical skill using the Bonedoc DHS simulator. Injury 39(10): 11271133.

37. Rambani R, Ward J, Viant W (2014) Desktop-based computer-assisted orthopedic training system for spinal surgery. J Surg Educ 71(6): 805809.

38. Rush R, Ginsberg HJ, Jenkinson R, Whyne CM (2008) Beyond the operating room: a simulator for sacroiliac screw insertion. Surg Innov 15(4): 321-323.

39. Gormley GJ, Collins K, Boohan M, Bickle IC, Stevenson M (2009) Is there a place for e-learning in clinical skills? A survey of undergraduate medical students' experiences and attitudes. Med Teach 31(1): e6-12.

40. Lau F, Bates J (2004) A review of e-learning practices for undergraduate medical education. J Med Syst 28: 71-87.

41. Stevens RJ (2011) Do trainees want e-learning in plastic surgery? J Plast Reconstr Aesthet Surg 64(2): e47-49.

42. Stevens RJ, Hamilton NM (2012) Is there a digital generation gap for e-learning in plastic surgery? J Surg Educ 69(3): 344-349.
43. Edelstein AI, Lovecchio FC, Saha S, Hsu WK, Kim JY (2014) Impact of resident involvement on orthopaedic surgery outcomes: An analysis of 30,628 patients from the american college of surgeons national surgical quality improvement program database. J Bone Joint Surg Am 96(15): e131.

44. Haughom BD, Schairer WW, Hellman MD, Yi PH, Levine BR (2014) Does resident involvement impact post-operative complications following primary total knee arthroplasty? An analysis of 24,529 cases. J Arthroplasty 29(7): 1468-1472.

45. Haughom BD, Schairer WW, Hellman MD, Yi PH, Levine BR (2014) Resident involvement does not influence complication after total hip arthroplasty: an analysis of 13,109 cases. J Arthroplasty 29(10): 19191924.

46. Auerbach JD, Lonner BS, Antonacci MD, Kean KE (2008) Perioperative outcomes and complications related to teaching residents and fellows in scoliosis surgery. Spine (Phila Pa 1976) 33(10): 1113-1118.

47. Pugely AJ, Gao Y, Martin CT, Callagh JJ, Weinstein SL, et al. (2014) The effect of resident participation on short-term outcomes after orthopaedic surgery. Clin Orthop Relat Res 472(7): 2290-2300.

48. Woolson ST, Kang MN (2007) A comparison of the results of total hip and knee arthroplasty performed on a teaching service or a private practice service. J Bone Joint Surg Am 89(3): 601-607.

49. Schoenfeld AJ, Serrano JA, Waterman BR, Bader JO, Belmont PJ (2013) The impact of resident involvement on post-operative morbidity and mortality following orthopaedic procedures: a study of 43,343 cases. Arch Orthop Trauma Surg 133(11): 1483-1491.

50. Moran M, Yap SL, Walmsley P, Brenkel IJ (2004) Clinical and radiologic outcome of total hip arthroplasty performed by trainee compared with consultant orthopedic surgeons. J Arthroplasty 19(7): 853-857.

51. Macario A (2010) What does one minute of operating room time cost? J Clin Anesth 22(4): 233-236.

52. Farnworth LR, Lemay DE, Wooldridge T, Mabrey JD, Blaschak MJ, et al. (2001) A comparison of operative times in arthroscopic ACL reconstruction between orthopaedic faculty and residents: the financial impact of orthopaedic surgical training in the operating room. Iowa Orthop J 21: 31-35.

53. Cannon WD, Garrett WE, Hunter RE, Sweeney HJ, Eckhoff DG, et al. (2014) Improving residency training in arthroscopic knee surgery with use of a virtual-reality simulator. A randomized blinded study. J Bone Joint Surg Am 96(21): 1798-1806.

54. Mabrey JD, Reinig KD, Cannon WD (2010) Virtual reality in orthopaedics: is it a reality? Clin Orthop Relat Res 468(10): 2586-2591.

55. Howells NR, Gill HS, Carr AJ, Price AJ, Rees JL (2008) Transferring simulated arthroscopic skills to the operating theatre: a randomised blinded study. J Bone Joint Surg Br 90(4): 494-499.

56. Waterman BR, Martin KD, Cameron KL, Owens BD, Belmont PJ (2016) Simulation training improves surgical proficiency and safety during diagnostic shoulder arthroscopy performed by residents. Orthopedics 39(3): e479-485.

57. Camp CL, Martin JR, Karam MD, Ryssman DB, Turner NS (2016) Orthopaedic Surgery Residents and Program Directors Agree on How Time Is Currently Spent in Training and Targets for Improvement. Clin Orthop Relat Res 474(4): 915-925.

58. Karam MD, Pedowitz RA, Natividad H, Murray J, Marsh JL (2013) Current and future use of surgical skills training laboratories in orthopaedic resident education: a national survey. J Bone Joint Surg Am 95(1): e4.

59. Lopez G, Wright R, Martin D, Jung J, Bracey D, et al. (2015) A cost-effective junior resident training and assessment simulator for orthopaedic surgical skills via fundamentals of orthopaedic surgery: AAOS exhibit selection. J Bone Joint Surg Am 97(8): 659-666. 
60. Angelo RL, Ryu RK, Pedowitz RA, Beach W, Burns J, et al. (2015) A Proficiency-based progression training curriculum coupled with a model simulator results in the acquisition of a superior arthroscopic bankart skill set. Arthroscopy 31(10): 1854-1871.

61. Karam MD, Westerlind B, Anderson DD, Marsh JL, Committee Corresponding UIOSST (2013) Development of an orthopaedic surgical skills curriculum for post-graduate year one resident learners - the University of Iowa experience. Iowa Orthop J 33: 178-184.

62. Ko JW, Lorzano A, Mirarchi AJ (2015) Effectiveness of a microvascular surgery training curriculum for orthopaedic surgery residents. J Bone Joint Surg Am 97(11): 950-955.

63. Brydges R, Carnahan H, Backstein D, Dubrowski A (2007) Application of motor learning principles to complex surgical tasks: searching for the optimal practice schedule. J Mot Behav 39(1): 40-48.

64. Dubrowski A, Backstein D, Abughaduma R, Leidl D, Carnahan H (2005) The influence of practice schedules in the learning of a complex boneplating surgical task. Am J Surg 190(3): 359-363.

65. Hansen S, Tremblay L, Elliott D (2005) Part and whole practice: chunking and online control in the acquisition of a serial motor task. Res Q Exerc Sport 76(1): 60-66.

66. Wenderoth N, Puttemans V, Vangheluwe S, Swinnen SP (2003) Bimanual training reduces spatial interference. J Mot Behav 35(3): 296-308.

67. Madan SS, Pai DR (2014) Role of simulation in arthroscopy training. Simul Healthc 9(2): 127-135.

68. Coughlin RP, Pauyo T, Sutton JC, Coughlin LP, Bergeron SG (2015) A validated orthopaedic surgical simulation model for training and evaluation of basic arthroscopic skills. J Bone Joint Surg Am 97(17): 1465-1471.

69. Gilmer BB, Guerrero DM, Coleman NW, Chamberlain AM, Warme WJ (2015) Orthopaedic residents improve confidence and knot-tying speed with a skills course. Arthroscopy 31(7): 1343-1348.

70. Pedowitz RA, Nicandri GT, Angelo RL, Ryu RK, Gallagher AG (2015) Objective assessment of knot-tying proficiency with the fundamentals of arthroscopic surgery training program workstation and knot tester. Arthroscopy 31(10): 1872-1879.

71. Karam MD, Kho JY, Yehyawi TM, Ohrt GT, Thomas GW, et al. (2012) Application of surgical skill simulation training and assessment in orthopaedic trauma. Iowa Orthop J 32: 76-82.

72. Insel A, Carofino B, Leger R, Arciero R, Mazzocca AD (2009) The development of an objective model to assess arthroscopic performance. J Bone Joint Surg Am 91(9): 2287-2295.

73. Camp CL, Krych AJ, Stuart MJ, Regnier TD, Mills KM, et al. (2016) Improving resident performance in knee arthroscopy: A prospective value assessment of simulators and cadaveric skills laboratories. J Bone Joint Surg Am 98(3): 220-225.
74. Van Heest A, Putnam M, Agel J, Shanedling J, McPherson S, et al. (2009) Assessment of technical skills of orthopaedic surgery residents performing open carpal tunnel release surgery. J Bone Joint Surg Am 91(12): 2811-2817.

75. Michelson JD (2006) Simulation in orthopaedic education: an overview of theory and practice. J Bone Joint Surg Am 88(6): 1405-1411.

76. Bergeson RK, Schwend RM, DeLucia T, Silva SR, Smith JE, et al. (2008) How accurately do novice surgeons place thoracic pedicle screws with the free hand technique? Spine (Phila Pa 1976) 33(15): E501-507.

77. Tortolani PJ, Moatz BW, Parks BG, Cunningham BW, Sefter J, et al. (2013) Cadaver training module for teaching thoracic pedicle screw placement to residents. Orthopedics 36(9): e1128-1133.

78. Angelo RL, Ryu RK, Pedowitz RA, Gallagher AG (2015) The bankart performance metrics combined with a cadaveric shoulder create a precise and accurate assessment tool for measuring surgeon skill. Arthroscopy 31(9): 1655-1670.

79. Hetaimish B, Elbadawi H, Ayeni OR (2016) Evaluating simulation in training for arthroscopic knee surgery: A systematic review of the literature. Arthroscopy 32(6): 1207-1220 e1201.

80. Reed JD, Stanbury SJ, Menorca RM, Elfar JC (2013) The emerging utility of composite bone models in biomechanical studies of the hand and upper extremity. J Hand Surg Am 38(3): 583-587.

81. Stirling ER, Lewis TL, Ferran NA (2014) Surgical skills simulation in trauma and orthopaedic training. J Orthop Surg Res 9: 126.

82. Egol KA, Phillips D, Vongbandith T, Szyld D, Strauss EJ (2015) Do orthopaedic fracture skills courses improve resident performance? Injury 46(4): 547-551.

83. Yehyawi TM, Thomas TP, Ohrt GT, Marsh JL, Karam MD, et al. (2013) A simulation trainer for complex articular fracture surgery. J Bone Joint Surg Am 95(13): e92.

84. Stirling ER, Lewis TL, Ferran NA, Pedowitz RA, Esch J, et al. (2002) Evaluation of a virtual reality simulator for arthroscopy skills development. Arthroscopy 18(6): E29.

85. Pettersson J, Palmerius KL, Knutsson H, Wahlstrom O, Tillander B, et al. (2008) Simulation of patient specific cervical hip fracture surgery with a volume haptic interface. IEEE Trans Biomed Eng 55: 1255-1265.

86. Seymour NE (2008) VR to OR: a review of the evidence that virtual reality simulation improves operating room performance. World J Surg 32(2): 182-188.

87. Seymour NE, Gallagher AG, Roman SA, O’Brien MK, Bansal VK, et al. (2002) Virtual reality training improves operating room performance: results of a randomized, double-blinded study. Ann Surg 236: 458-463.

88. Zevin B, Aggarwal R, Grantcharov TP (2014) Surgical simulation in 2013: why is it still not the standard in surgical training? J Am Coll Surg 218(2): 294-301. 